\title{
Fructose malabsorption
}

\author{
Karolin Ebert ${ }^{1,2,3}$ and Heiko Witt ${ }^{1,2,3^{*}}$
}

\begin{abstract}
Incomplete intestinal absorption of fructose might lead to abdominal complaints such as pain, flatulence and diarrhoea. Whether defect fructose transporters such as GLUT5 or GLUT2 are involved in the pathogenesis of fructose malabsorption is a matter of debate. The hydrogen production by colonic bacteria is used for diagnosis with the hydrogen breath test. However, the appropriate fructose test dose for correct diagnosis is unclear. Subjects with fructose malabsorption show increased breath hydrogen levels and abdominal symptoms after fructose administration but do not report any symptoms when fructose is given together with glucose. This beneficial effect of glucose, however, cannot be explained yet but might be used for clinical care of these subjects.
\end{abstract}

Keywords: Fructose malabsorption, Glucose transporters, GLUTs, Hydrogen breath test

\section{Background}

The complex process of sugar digestion and absorption can be disturbed due to defect digestion enzymes or monosaccharide transporters. Lactose malabsorption is caused by variants in the promoter region of the $L C T$ gene coding for lactase-phlorizin hydrolase. Consequently, the cleavage of lactose in its components glucose and galactose is impaired [1]. In patients with glucose-galactose malabsorption, mutations in the SLC5A1 coding region result in truncated or mistargeted glucose-galactose transporter SGLT1. Due to impaired absorption of glucose and galactose, newborns develop life-threatening diarrhoea and dehydration [2]. The molecular and the genetic causes of fructose malabsorption are unknown. Like other sugar malabsorptions, the disease is characterized by colicky abdominal pain, flatulence and diarrhoea. These symptoms are caused by bacterial fermentation of unabsorbed fructose in the colon resulting in production of hydrogen, carbon dioxide, methane and short-chain fatty acids. Moreover, the increased sugar load in the colon might cause osmotic diarrhoea (Fig. 1). Patients should avoid fructose-rich food such as apples, pears and red peppers. Nutrition anamnesis is often not helpful for making diagnosis since affected subjects instinctively avoid fructoserich foods. For therapy, the beneficial effect of glucose on

\footnotetext{
* Correspondence: heiko.witt@|rz.tum.de

${ }^{1}$ Pädiatrische Ernährungsmedizin, Klinikum rechts der Isar (MRI), Technische Universität München (TUM), Gregor-MendelStr. 2, 85354 Freising, Germany ${ }^{2}$ Else Kröner-Fresenius-Zentrum für Ernährungsmedizin (EKFZ), Technische Universität München (TUM), Gregor-MendelStr. 2, 85354 Freising, Germany Full list of author information is available at the end of the article
}

fructose absorption is used. Patients tolerate fruits such as bananas or grapefruits which contain fructose and glucose in at least equimolar concentrations. Apples are not tolerated because of their high fructose (7 g/apple) and lower glucose (2.3 g/apple) content (ratio 3:1). Furthermore, the simultaneous intake of glucose can avoid symptoms after fructose consumption.

\section{Are sugar transporter defects responsible for fructose malabsorption?}

Since GLUT5 represents the main intestinal fructose transporter, its involvement in the pathophysiology of fructose malabsorption seems obvious. Glut5 knock-out mice demonstrated decreased fructose uptake in the jejunum and reduced plasma fructose levels compared to their littermates. However, intestinal fructose transport is not completely abolished indicating the presence of other intestinal fructose transporters. The feeding of a diet containing $60 \%$ fructose for 14 days resulted in increased GLUT5 expression in mice [3]. Whether fructose absorption can be enhanced by increased GLUT5 expression due to fructoserich diet in humans is not investigated so far.

The GLUT5 coding region was analyzed using SSCP (single-strand conformational polymorphism) in 8 children with fructose malabsorption, 6 healthy controls and 13 healthy parents of patients [4]. The patients were diagnosed by hydrogen breath testing with $1 \mathrm{~g} / \mathrm{kg}$ fructose and occurrence of symptoms during the test. No GLUT5 variant was found that correlated with the occurrence of fructose malabsorption. Nevertheless, an involvement of GLUT5 in

\section{Springer}

(c) 2016 Ebert and Witt. Open Access This article is distributed under the terms of the Creative Commons Attribution 4.0 International License (http://creativecommons.org/licenses/by/4.0/), which permits unrestricted use, distribution, and reproduction in any medium, provided you give appropriate credit to the original author(s) and the source, provide a link to the Creative Commons license, and indicate if changes were made. 


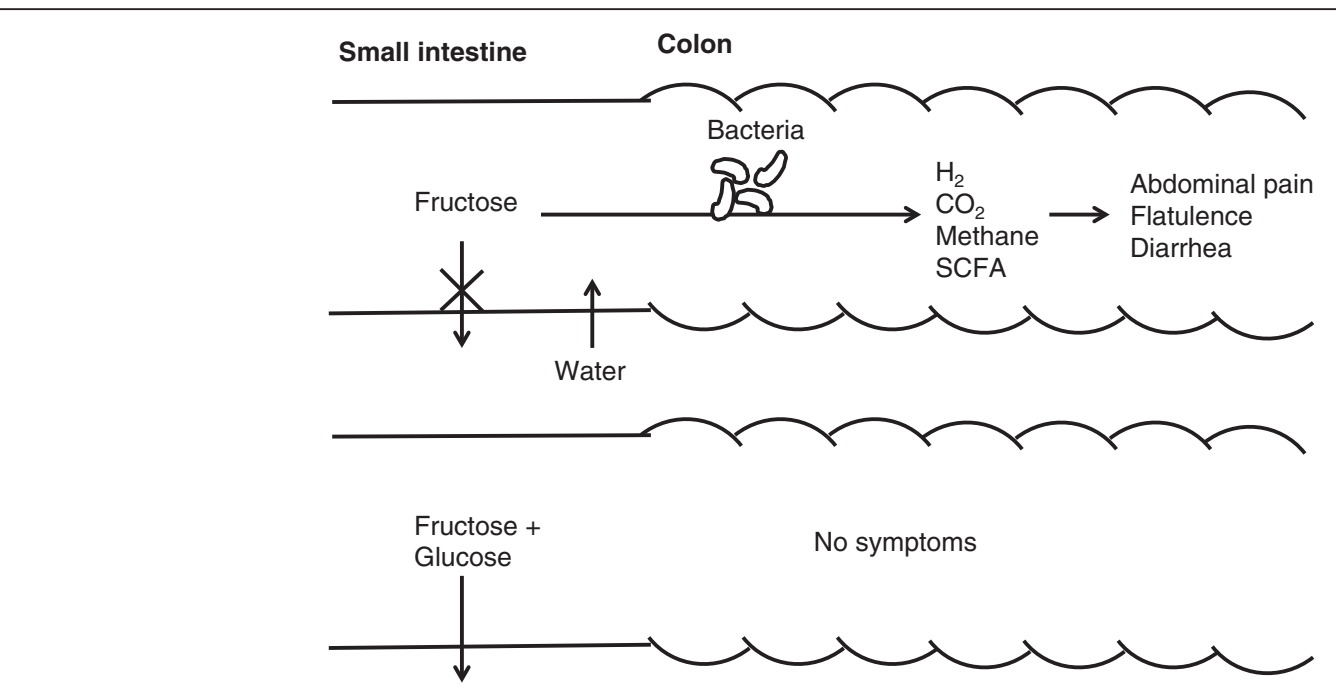

Fig. 1 Symptom generation in fructose malabsorption. As consequence of impaired absorption, fructose reaches the colon and is metabolized by colonic bacteria. The products hydrogen, carbon dioxide, methane and short-chain fatty acids (SCFA) and the osmotic water influx cause the typical symptoms. The additional consumption of equimolar amounts of glucose enhances fructose absorption and prevents symptoms

the pathophysiology of fructose malabsorption cannot be excluded since this cohort was quite small, the age of patients was very young (ranging from 8 months to 5 years, median 2.75 years) and half of the patients showed positive sucrose breath test questioning the diagnosis of isolated fructose malabsorption [4]. Moreover, SSCP analysis has a low sensitivity compared to DNA sequencing, and noncoding regions were not investigated in this study.

Other fructose transporters such as GLUT2 or SGLT4 are also present in the small intestine and might play a pathogenic role in this condition (Fig. 2) [5-7]. GLUT2 is expressed in the basolateral membrane but the

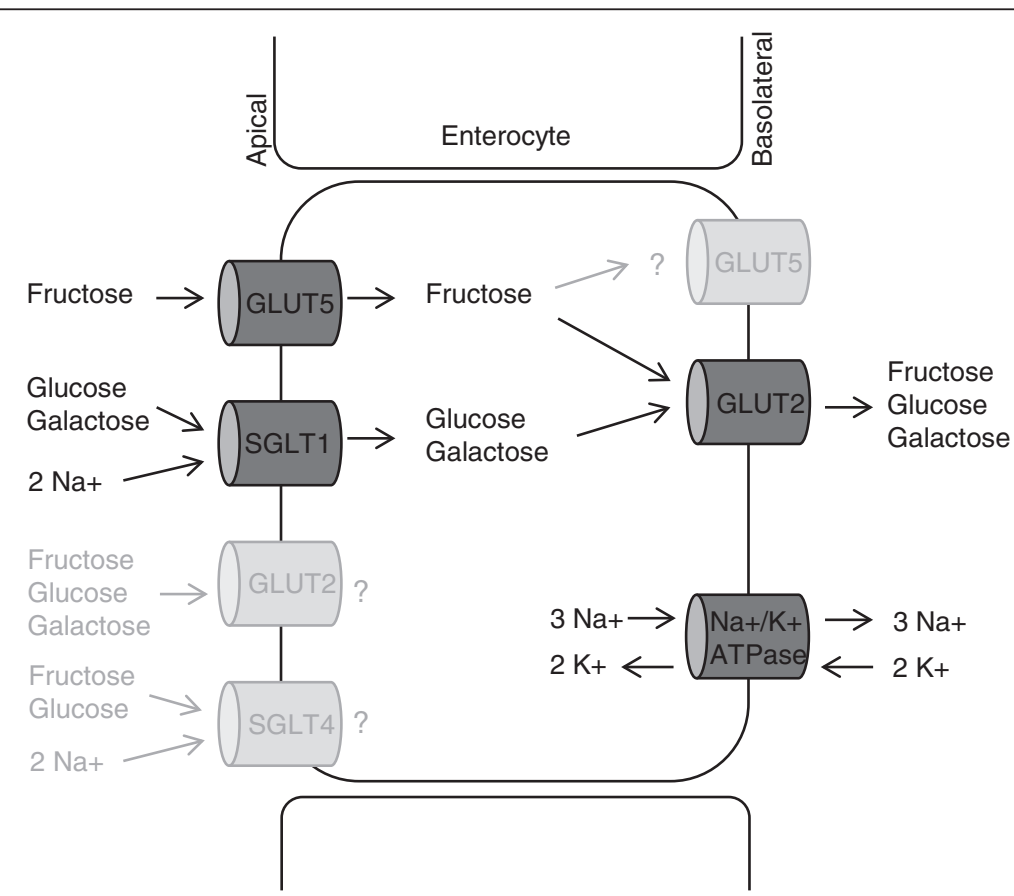

Fig. 2 Intestinal sugar transport. Fructose is transported into the enterocyte by GLUT5 and glucose and galactose by SGLT1. Exit of fructose, glucose and galactose is provided by GLUT2. The presence and relevance of GLUT2 and SGLT4 in the apical membrane and GLUT5 in the basolateral membrane are under debate. Verified transport routes are illustrated in dark grey, hypothetical in light grey 
presence in the apical membrane is questionable $[8,9]$. If GLUT2 is responsible for the exit of fructose only, an important role for fructose malabsorption is unlikely. GLUT2 mutations are associated to Fanconi-Bickel syndrome, an autosomal recessive inherited disorder characterized by hepatorenal glycogen accumulation, renal tubular dysfunction and glucose/galactose intolerance. However, no disturbed fructose absorption has been reported in this disease [10].

The hypothesis that intestinal GLUT5 or GLUT2 expression is reduced in fructose malabsorption was tested by Wilder-Smith et al. in 11 adults with fructose malabsorption (positive breath test after ingestion of $35 \mathrm{~g}$ fructose in combination with abdominal symptoms) and 15 control subjects. The messenger RNA (mRNA) content and protein expression of GLUT5 and GLUT2 was similar in both groups [11].

Unlike GLUT5 and GLUT2, SGLT4 provides Na ${ }^{+}$-dependent secondary active transport of glucose and possibly fructose. Fructose transport by SGLT4 was not directly shown but an inhibition of glucose uptake by fructose was demonstrated. So far, the expression of SGLT4 in the apical membrane and its role for intestinal fructose absorption has not been investigated [6].

\section{Is the hydrogen breath test appropriate for diagnosis?}

Fructose malabsorption is usually diagnosed by hydrogen breath test (HBT). Since the absorption capacity for fructose is limited in healthy people also, the appropriate fructose dose for this test is under discussion. After ingestion of $50 \mathrm{~g}$ fructose, $58 \%$ of 102 subjects demonstrated incomplete absorption with a rise in breath hydrogen over the arbitrarily defined threshold level of $20 \mathrm{ppm}$. In these subjects, $25 \%$ reported abdominal symptoms during the test period. Twenty-one persons with a positive breath test after ingestion of $50 \mathrm{~g}$ fructose repeated the procedure with $25 \mathrm{~g}$ fructose. With this lower dose, only $11 \%$ showed incomplete absorption. Moreover, of the $11 \%$ who had abdominal symptoms, only one person showed an elevated breath hydrogen level [12]. Rao and co-workers conducted a double-blind study with 20 healthy subjects: all subjects exhibited negative HBT with $15 \mathrm{~g}$ fructose. Two subjects (10\%) showed incomplete absorption with a dose of $25 \mathrm{~g}$ fructose but did not report symptoms. After administration of $50 \mathrm{~g}$ fructose, $80 \%$ of subjects showed breath hydrogen rise over baseline and $55 \%$ demonstrated abdominal symptoms [13]. When 31 children received $2 \mathrm{~g}$ fructose per $\mathrm{kg}$ bodyweight (max. $50 \mathrm{~g}$ ), $71 \%$ showed positive breath test and $13 \%$ had abdominal symptoms [14]. As shown by these and other studies, a dose of $50 \mathrm{~g}$ (corresponds to approximately seven medium-sized apples) in adults or $2 \mathrm{~g} / \mathrm{kg}$ in children exceeds in the majority the intestinal absorption capacity whereas the administration of $\leq 25 \mathrm{~g}$ fructose in adults or $\leq 1 \mathrm{~g} / \mathrm{kg}$ in children is thought to be appropriate for diagnosis of fructose malabsorption. Until the reason for fructose malabsorption is unclear, it is hardly possible to define the right dose for HBT and to discriminate between normal and abnormal. Therefore, it is difficult to estimate the prevalence in the general population. A detailed review about hydrogen breath testing in fructose malabsorption was published by Jones et al. [15].

\section{Age dependence of fructose absorption}

There is evidence that the prevalence of fructose malabsorption correlates with the age. After administration of $1 \mathrm{~g} / \mathrm{kg}$ fructose, 16 out of 23 children aged $1-3$ years showed elevated peak hydrogen excretion, whereas only 7 out of 26 older children (4-6 years) demonstrated increased breath hydrogen levels. Furthermore, peak hydrogen was higher in the younger age group [16]. A clear correlation between age and HBT $(0.5 \mathrm{~g} / \mathrm{kg}$, max. $10 \mathrm{~g}$ fructose) was found in a study population of 1093 children and adults, where fructose absorption capacity was rising up to the age of 10 years. From the age of 10 to 79, no differences were observed regarding absorption capacity [17]. On the contrary, the prevalence of lactose intolerance is low in infants and rises with the age. In pediatric populations from Finland and Somalia, the lactase activity decreased mainly between 5 and 10 years of age [18].

\section{The beneficial effect of glucose}

The simultaneous ingestion of glucose can improve fructose absorption and prevent symptoms. In 1984, it was described that children showed increased breath hydrogen excretion after administration of $2 \mathrm{~g} / \mathrm{kg}$ (max. $50 \mathrm{~g}$ ) fructose but not after ingestion of fructose together with equimolar amounts of glucose or galactose. Only the three children with the highest breath hydrogen peaks demonstrated abdominal symptoms [14]. This effect was confirmed by Rumessen et al. in 10 healthy adults. An elevated breath hydrogen excretion after ingestion of $50 \mathrm{~g}$ fructose was observed in 7 out of 10 people. In contrast, breath hydrogen peaks were normal after simultaneous ingestion of equimolar amounts glucose [19]. Patients with fructose malabsorption can additionally consume glucose if they want to eat fructose-rich food to avoid symptoms. The reason for this absorption enhancing effect is under discussion. Fructose could be passively absorbed due to glucosestimulated water absorption. The observation that this beneficial effect was not only mediated by sugars but also by amino acids such as alanine supports this hypothesis [20]. However, fructose transport was not enhanced after ingestion of fructose and urate in equal amounts [14]. Another explanation is the presence of a glucose dependent fructose co-transport system [19]. An involvement of the 
fructose and glucose transporter GLUT2 has been proposed because trafficking of GLUT2 to the apical membrane after glucose load was observed in rats [8]. In contrast, no evidence for GLUT2 presence in the apical brush-border membrane in response to glucose was shown by Röder et al. indicating the involvement of other transporters [9]. In a cohort of six healthy subjects, it was observed that glucose and galactose can prolongate gastric emptying [21]. Possibly, the delayed arrival of fructose in the small intestine due to delayed gastric emptying could explain the increased fructose absorption by simultaneous glucose administration. Moreover, an enhancing effect of glucose and lipids on sorbitol absorption was demonstrated which might be explained by similar mechanisms [22].

\section{Fructose malabsorption as cause for recurrent abdominal pain}

Gijsbers et al. conducted a double-blinded placebocontrolled (DBPC) trial in children with recurrent abdominal pain. First, 121 children performed a HBT with $2 \mathrm{~g} / \mathrm{kg}$ fructose (max. $50 \mathrm{~g}$ ). From those children who were positive $(65 \%), 49$ were set on a fructose elimination diet. Sixty-five percent of them reported absence of symptoms during the diet but only 13 out of 31 children (41\%) responded to an open provocation with fructose. Finally, all 8 children which demonstrated symptoms after provocation, showed no symptoms after double-blinded placebocontrolled re-provocation. In summary, none of the children demonstrated positive hydrogen breath test together with the absence of symptoms during elimination and symptoms during the DBPC trial. An explanation why the children showed positive hydrogen breath test after fructose ingestion but no symptoms during DBPC with fructose could be the different dose. During the breath test, a maximum of $50 \mathrm{~g}$ fructose $(2 \mathrm{~g} / \mathrm{kg})$ was given whereas in the DBPC trial, $25 \mathrm{~g}$ was consumed over the whole day. However, factors such as the gut microbiota, transit time and diet composition might also cause varying fructose tolerance [23]. As mentioned above, $2 \mathrm{~g} / \mathrm{kg}$ fructose cannot be completely absorbed in the majority of children. Therefore, the dose is too high to discriminate between fructose absorption and malabsorption. Since the elimination and provocation was conducted at home, it is possible that children did not strictly follow the elimination and provocation guidelines leading to inconsistent results. Nevertheless, fructose malabsorption was most likely not the prominent factor for abdominal pain in this cohort.

\section{Dietary fructose restriction in IBS}

High-fructose consumption can trigger symptoms in patients with irritable bowel syndrome (IBS). With a dose of $25 \mathrm{~g}$ fructose, $22 \%$ (20/90) of IBS patients showed positive hydrogen breath test. Amongst fructose malabsorbers,
$35 \%$ had abdominal symptoms during the test whereas $26 \%$ of the fructose absorbers demonstrated symptoms [24]. With the same fructose dose, $10 \%(2 / 20)$ of healthy adults demonstrated elevated breath hydrogen without any symptoms [13]. Fructose intake is restricted within the low FODMAP (fermentable oligo-, di- and monosaccharides and polyols) diet often recommended for IBS patients. In a cohort of 90 IBS patients, symptoms improved during this diet. Moreover, the occurrence of fructose malabsorption was associated with improvement of symptoms [25]. A further study in 67 IBS patients showed symptom amelioration after standard IBS diet and low FODMAP diet without significant differences between the two diets [26]. However, potential undesirable side-effects of long-term restricted diets should be taken into account.

\section{Conclusion}

The pathophysiology of fructose malabsorption remains unclear. If there are genetic or epigenetic variations in intestinal fructose transporters such as GLUT5, GLUT2 or SGLT4 needs to be elucidated. Genetic variants within the GLUT5 coding regions are unlikely but not excluded as reason for impaired fructose absorption. There are first hints that GLUT5 and GLUT2 expression is not lower in affected subjects. Probably, there are different mechanisms leading to this condition. To elucidate the underlying mechanism, genetic analysis in well-defined cases and controls should be performed either by candidate gene approach or complete genome sequencing. Because the absorption capacity for fructose is highly individual, it is difficult to determine the right dose for HBT. There is agreement that $50 \mathrm{~g}$ fructose in adults or $2 \mathrm{~g} / \mathrm{kg}$ fructose in children exceed the absorption capacity of the majority. A dose of $\leq 25 \mathrm{~g}$ in adults or $\leq 1 \mathrm{~g} / \mathrm{kg}$ in children seems to be appropriate. The variance of breath test results at different times of the day and the reproducibility should be assessed. It remains unclear why increased gas production in the intestine during HBT does not necessarily cause abdominal symptoms. Possible, the intestinal sensitivity and pain perception is highly individual. Whether fructose malabsorption is more common in IBS patients needs to be verified. However, restriction of fructose and other fermentable saccharides can be helpful in therapy. To clarify the absorption enhancing effect of glucose, it is important to understand the mechanisms of intestinal sugar transport and to gain insights into possible interactions of sugar transporters. To address this question, future studies should verify the assumption that different amino acids also promote fructose absorption.

Abbreviations

DBPC: double-blinded placebo-controlled; GLUT: glucose transporter; HBT: hydrogen breath test; SSCP: single-strand conformational polymorphism. 


\section{Competing interests}

The authors declare that they have no competing interests.

\section{Authors' contributions}

KE has written the manuscript. HW revised the manuscript. Both authors read and approved the final manuscript.

\section{Acknowledgements}

This work was supported by Deutsche Forschungsgemeinschaft (GRK 1482)

\section{Author details}

${ }^{1}$ Pädiatrische Ernährungsmedizin, Klinikum rechts der Isar (MRI), Technische Universität München (TUM), Gregor-MendelStr. 2, 85354 Freising, Germany. ${ }^{2}$ Else Kröner-Fresenius-Zentrum für Ernährungsmedizin (EKFZ), Technische Universität München (TUM), Gregor-MendelStr. 2, 85354 Freising, Germany. ${ }^{3}$ Zentralinstitut für Ernährungs- und Lebensmittelforschung (ZIEL), Technische Universität München (TUM), Gregor-MendelStr. 2, 85354 Freising, Germany.

Received: 15 December 2015 Accepted: 4 February 2016

Published online: 16 February 2016

\section{References}

1. Enattah NS, Sahi T, Savilahti E, Terwilliger JD, Peltonen L, Järvelä I (2002) Identification of a variant associated with adult-type hypolactasia. Nat Genet 30:233-237

2. Wright EM, Turk E, Martin MG (2002) Molecular basis for glucose-galactose malabsorption. Cell Biochem Biophys 36:115-121

3. Barone S, Fussell SL, Singh AK, Lucas F, Xu J, Kim C, Wu X, Yu Y, Amlal H, Seidler U, Zuo J, Soleimani M (2009) Slc2a5 (Glut5) is essential for the absorption of fructose in the intestine and generation of fructose-induced hypertension. J Biol Chem 284:5056-5066

4. Wasserman D, Hoekstra JH, Tolia V, Taylor CJ, Kirschner BS, Takeda J, Bell Gl, Taub R, Rand EB (1996) Molecular analysis of the fructose transporter gene (GLUT5) in isolated fructose malabsorption. J Clin Invest 98:2398-2402

5. Gould GW, Thomas HM, Jess TJ, Bell Gl (1991) Expression of human glucose transporters in Xenopus oocytes: kinetic characterization and substrate specificities of the erythrocyte, liver, and brain isoforms. Biochemistry 30 : 5139-5145

6. Tazawa S, Yamato T, Fujikura H, Hiratochi M, Itoh F, Tomae M, Takemura Y, Maruyama H, Sugiyama T, Wakamatsu A, Isogai T, Isaji M (2005) SLC5A9/SGLT4, a new Na+-dependent glucose transporter, is an essential transporter for mannose, 1,5-anhydro-D-glucitol, and fructose. Life Sci 76:1039-1050

7. Blakemore SJ, Aledo JC, James J, Campbell FC, Lucocq JM, Hundal HS (1995) The GLUT5 hexose transporter is also localized to the basolateral membrane of the human jejunum. Biochem J 309:7-12

8. Kellett GL, Helliwell PA (2000) The diffusive component of intestinal glucose absorption is mediated by the glucose-induced recruitment of GLUT2 to the brush-border membrane. Biochem J 350:155-162

9. Röder PV, Geillinger KE, Zietek TS, Thorens B, Koepsell H, Daniel H (2014) The role of SGLT1 and GLUT2 in intestinal glucose transport and sensing. PLoS One. e89977 doi: 10.1371/journal.pone.0089977.

10. Santer R, Groth S, Kinner M, Dombrowski A, Berry GT, Brodehl J, Leonard J Moses S, Norgren S, Skovby F, Schneppenheim R, Steinmann B, Schaub J (2002) The mutation spectrum of the facilitative glucose transporter gene SLC2A2 (GLUT2) in patients with Fanconi-Bickel syndrome. Hum Genet 110:21-29

11. Wilder-Smith CH, Li X, Ho SS, Leong SM, Wong RK, Koay ES, Ferraris RP (2014) Fructose transporters GLUT5 and GLUT2 expression in adult patients with fructose intolerance. United European Gastroenterol J 2:14-21

12. Truswell AS, Seach JM, Thorburn AW (1988) Incomplete absorption of pure fructose in healthy subjects and the facilitating effect of glucose. Am J Clin Nutr 48:1424-1430

13. Rao SSC, Attaluri A, Anderson L, Stumbo P (2007) Ability of the normal human small intestine to absorb fructose: evaluation by breath testing. Clin Gastroenterol Hepatol 5:959-963

14. Kneepkens CM, Vonk RJ, Fernandes J (1984) Incomplete intestinal absorption of fructose. Arch Dis Child 59:735-738

15. Jones HF, Butler RN, Moore DJ, Brooks DA (2013) Developmental changes and fructose absorption in children: effect on malabsorption testing and dietary management. Nutr Rev 71:300-309

16. Hoekstra JH, van Kempen AA, Bijl SB, Kneepkens CM (1993) Fructose breath hydrogen tests. Arch Dis Child 68:136-138
17. Jones HF, Burt E, Dowling K, Davidson G, Brooks DA, Butler RN (2011) Effect of age on fructose malabsorption in children presenting with gastrointestinal symptoms. J Pediatr Gastroenterol Nutr 52:581-584

18. Rasinperä H, Kuokkanen M, Kolho K, Lindahl H, Enattah NS, Savilahti E, Orpana A, Järvelä I (2005) Transcriptional downregulation of the lactase (LCT) gene during childhood. Gut 54:1660-1661

19. Rumessen JJ, Gudmand-Høyer E (1986) Absorption capacity of fructose in healthy adults. Comparison with sucrose and its constituent monosaccharides. Gut 27:1161-1168

20. Hoekstra $J H$, van den Aker JH (1996) Facilitating effect of amino acids on fructose and sorbitol absorption in children. J Pediatr Gastroenterol Nutr 23:118-124

21. Elias E, Gibson GJ, Greenwood LF, Hunt JN, Tripp JH (1968) The slowing of gastric emptying by monosaccharides and disaccharides in test meals. J Physiol 194:317-326

22. Beaugerie L, Flourié B, Lémann M, Achour L, Franchisseur C, Rambaud JC (1995) Sorbitol absorption in the healthy human small intestine is increased by the concomitant ingestion of glucose or lipids. Eur J Gastroenterol Hepatol 7:125-128

23. Gijsbers CF, Kneepkens CM, Büller HA (2012) Lactose and fructose malabsorption in children with recurrent abdominal pain: results of double-blinded testing. Acta Paediatr 101:e411-e415. doi:10.1111/j.1651-2227.2012.02721.x

24. Melchior C, Gourcerol G, Déchelotte P, Leroi AM, Ducrotté P (2014) Symptomatic fructose malabsorption in irritable bowel syndrome: a prospective study. United European Gastroenterol J 2:131-137

25. de Roest RH, Dobbs BR, Chapman BA, Batman B, O'Brian LA, Leeper JA, Hebblethwaite CR, Gearry RB (2013) The low FODMAP diet improves gastrointestinal symptoms in patients with irritable bowel syndrome: a prospective study. Int J Clin Pract 67:895-903

26. Böhn L, Störsrud S, Liljebo T, Collin L, Lindfors $P$, Törnblom H, Simrén M (2015) Diet low in FODMAPs reduces symptoms of irritable bowel syndrome as well as traditional dietary advice: a randomized controlled trial. Gastroenterology 149:1399-1407,e2

\section{Submit your manuscript to a SpringerOpen ${ }^{\circ}$ journal and benefit from:}

- Convenient online submission

- Rigorous peer review

- Immediate publication on acceptance

- Open access: articles freely available online

- High visibility within the field

- Retaining the copyright to your article

Submit your next manuscript at $>$ springeropen.com 